\title{
cosmetics
}

ISSN 2079-9284

www.mdpi.com/journal/cosmetics

Article

\section{Hair Dye-DNA Interaction: Plausible Cause of Mutation}

\section{Swati Maiti ${ }^{1}$, Sudarson Sekhar Sinha ${ }^{2}$ and Mukesh Singh ${ }^{1, *}$}

1 Department of Biotechnology, Haldia Institute of Technology, HIT campus, Hatiberia, Purba Medinipur, Haldia 721657, India; E-Mail: swatimaiti.bt@gmail.com

2 Department of Chemistry and Biochemistry, Jackson State University, 1400 John R. Lynch Street, Jackson, MS 39217-0510, USA; E-Mail: sudarson.s.sinha@jsums.edu

* Author to whom correspondence should be addressed; E-Mails: msingh006@gmail.com or singhmukesh@hithaldia.in; Tel.: +91-03224-252-850 (ext 234); Fax: +91-03224-252-800.

Academic Editor: Enzo Berardesca

Received: 12 July 2015 / Accepted: 22 September 2015 / Published: 25 September 2015

\begin{abstract}
Hair dye is one of the most popular cosmetic products which are used more widely and frequently to improve an individual's appearance. Although the genotoxic effects of dye ingredients are widely reported, hair dye in its usable form is not reported extensively. In this contribution, we report the possible mode of interaction of hair dye with DNA which leads to genotoxicity. The effect of dye DNA interaction was studied on the most popular and globally used hair dye with Calf Thymus DNA and plasmid DNA. This interaction of dye DNA was studied by spectroscopic analyses and gel electrophoresis. The result had shown positive interaction of dye with DNA. Gel electrophoresis study confirms the binding of dye with DNA which results in linearization and fragmentation of the plasmid DNA. Dye-DNA interaction causes fragmentation and oxidation of DNA in absence of any catalyst, implies high toxicity of commercial hair dyes. Thus, it can be deduced from the present studies that hair dye in its usable form may lead to its penetration through skin affecting genomic DNA possesses genotoxic property and can be treated as one of the most common mutagen.
\end{abstract}

Keywords: DNA damage; DNA interaction; hair dye; spectroscopic studies 


\section{Introduction}

From the beginning of civilization, hair has played an important role in attractiveness, youthfulness and beauty [1]. In modern times, not only do elderly people dye their gray hair but it has also become a fashion, for both girls and boys to color their hair. As the demand for hair dyes has grown to a higher scale, in order to make the products more effective in terms of longitivity of colors, hair dyes are mostly of oxidative type. It is the most preferable one due to its stability [2,3]. It contains primary intermediates, couplers or modifiers, oxidants and alkaline agents which include $p$-phenylenediamine ( $p$-PD), $p$-toluenediamine ( $p$-TD), substituted $p$-diamines, ortho- or para-aminophenols ( $o$-AP or $p$-AP), meta-substituted aromatic derivatives, resorcinol, hydrogen peroxide, urea peroxide, sodium percarbonate or perborate, ammonia, monoethanolamine or aminomethylpropanol [4]. In 1975, the results of Ames test on oxidative hair dye ingredients suggested that nearly $90 \%$ of permanent hair dye ingredients were mutagenic and might therefore pose a carcinogenic risk to consumers [5]. After this observation, chemicals present in permanent hair dyes, particularly aromatic amines, are studied vividly. Results have shown that hair dye ingredients and their residual products are genotoxic [6-11] and even penetrate skin [12-14].

Alhough much work has been done with individual components or with $p$-phenylenediamine ( $p$-PD), Hydrogen peroxide $\left(\mathrm{H}_{2} \mathrm{O}_{2}\right)$ and resorcinol, no work has been done to check the effect of dye in its usable form which contains some other ingredients along with the above chemicals to enhance the color. From the previous studies it has also been seen that the genotoxicity of the ingredients may depend on the ambient conditions [15], duration of exposure [16], ratio of aromatic amines with other ingredients [16-18] and storage of dye [16,19]. So, we performed our all experiments under the required conditions (duration of exposure, ambient atmosphere and hair dye in its usable form) resembling the chemistry of oxidative hair color. In our unpublished work, we observed the chromosomal aberration/micronucleus formation in Allium cepa root tip when the root was treated with dye [20]. The chromosomal abnormalities indicate the genotoxic nature of dye. However, the detailed mechanism of toxicity was not studied. So, our goal was to investigate the mechanism of dye-DNA interaction. As a primary step towards this, the present study involves statistical analysis on frequency of use, health problems associated with dye usage, brand, etc., in a questionnaire form to select the best brand. From the statistical analysis, the "best" one, which was an oxidative hair dye of dark shade was selected. Over recent years, spectroscopic studies have become an efficient technique to explore the binding interaction of ligand with DNA and protein [21,22]. To obtain an in-depth understanding of the toxicity of hair dye, we carried out a detailed spectroscopic study of dye DNA interaction.

\section{Experimental Section}

\subsection{Materials}

All the chemicals used in the experiment were of analytical quality and used without any further purification. Calf thymus DNA and plasmid DNA (pUC 18) were purchased from Gene Link (Hawthorne, NY, USA). A solution of $10 \mathrm{mg} / \mathrm{mL}$ of DNA stock was prepared in phosphate buffer. Oxidative hair dye was purchased from a local market. Dye was prepared in its usable form by adding color and developer as prescribed amount mentioned and then $100 \mathrm{mg} / \mathrm{mL}$ working stock was prepared 
by adding phosphate buffer ( $\mathrm{pH} 7.8$ ). We used the sample immediately after the preparation. Some of the major ingredients present in usable form of dye are $p$-phenylenediamine ( $p$-PD), $m$-aminophenol ( $m$-AP), resorcinol and hydrogen peroxide. The usable form of sample hair dye contains $0.95 \% p$-PD as mentioned in the ingredient list.

\subsection{Spectroscopic Studies of Dye-DNA Interaction}

\subsubsection{Interaction of Dye with DNA}

The dye-DNA interaction was studied vividly to find out the mechanism of interactions which ultimately lead to the genotoxic effect of hair dye. To check the interaction of dye with DNA, dye DNA conjugate was prepared by adding the calculated amount of dye in DNA solution and was incubated for $30 \mathrm{~min}$ at room temperature. The concentration of DNA in the sample was taken as $1 \mathrm{mg} / \mathrm{mL}$. Steady state absorption and emission were measured with Shimadzu spectrophotometer (Kyoto, Japan) UV-1700 and PerkinElmer fluorescence spectrophotometer LS55 (Waltham, MA, USA).

\subsubsection{Dye-DNA Interaction in Sodium Dodecyl Sulfate (SDS) Micelles}

To confirm the interaction of dye, an absorption and emission study of the dye in SDS micelle was done. SDS micelle is a famous system to study molecular dynamics of any chemical [23]. SDS micelle was negatively charged and DNA was also negatively charged. If dye shows interaction with SDS micelle dye, the result could be a similar kind of interaction with DNA [21]. So, our objective was to check how dye interacts with SDS micelle. SDS micelle was prepared by adding the calculated amount of SDS in a known volume of buffer solution and stirring for about $30 \mathrm{~min}$ and was studied further.

\subsubsection{UV-Vis Spectroscopic Studies on Autoxidation of Dye}

Previous studies [8,9] have shown that some hair dye components like $p$-aminophenol ( $p$-AP), $o$-phenylenediamine (o-PD) and its derivatives and 4-chloro-o-phenylenediamine(Cl-o-PD) and 4-nitro- $O$-phenylenediamine $\left(\mathrm{NO}_{2}-O-\mathrm{PD}\right)$ produce oxidative DNA damage same as that induced by $\mathrm{Fe}(\mathrm{III})$ or $\mathrm{Cu}(\mathrm{II})$. To check the possibility of autoxidation, spectroscopic studies had been performed on commercial hair dyes in presence and absence of Fe(III). A quantity of $2 \mu \mathrm{g}$ dye in phosphate buffer ( $\mathrm{pH}$ 7.8) was studied in the presence and absence of $20 \mu \mathrm{M}$ Fe (III). UV-Vis spectra of the dye solution were measured every $10 \mathrm{~min}$ for $30 \mathrm{~min}$ at $37^{\circ} \mathrm{C}$.

\subsection{Study of Dye-DNA Interaction Using Agarose Gel Electrophoresis}

It was seen from our previous study that agarose gel electrophoresis can be used to check the nature of binding of dye with DNA [21]. So, to reconfirm the binding nature of dye with DNA and to check the effect of interaction on DNA, integrity agarose gel electrophoresis was carried out by standard procedure with calf thymus DNA and also with plasmid DNA (pUC 18). For this purpose DNA loading wells were made in the middle of the gel, so that movement of dye, dye-DNA and DNA can be examined under electric field based on the nature of charge. From this study, electric nature of dye can also be predicted. Ethidium Bromide (EB) was used as a reference for positively charged dye. Gel 
pictures were collected from the gel system of Vilber Lourmat model no. ECX 20.M. Dye DNA complexes were made by adding different concentration of dye with DNA and incubation for 30 min at $25^{\circ} \mathrm{C}$.

\subsection{Statistical Analysis}

All experiments were carried out at least three times. Data points were represented by the mean of the measured values. Statistical analysis was carried out using Origin and MS-Excel software.

\section{Results and Discussions}

\subsection{Spectroscopic Study of Dye-DNA Interaction}

In order to check the effects of dye on DNA, calf thymus DNA was used with different concentrations of dye. From the deconvolution of the dye components from dye-DNA conjugate, we have found $\sim 10 \mathrm{~nm}$ blue shift as compared to water. Figure 1 represents the absorbance peak shift with different concentrations of dye in presence and absence of DNA. Such phenomena had been observed when the surroundings polarity of a molecule, whose absorbance band is due to $n$ to $\pi^{*}$ transition, was increased [24]. It has been reported that several groups of the dye contain $-\mathrm{NH}_{2}$ groups containing lone pair electrons [4]. Due to high polarity of the medium, the stabilization of the ground state is more than the excited states, increasing the energy gap between ground state and excited state.

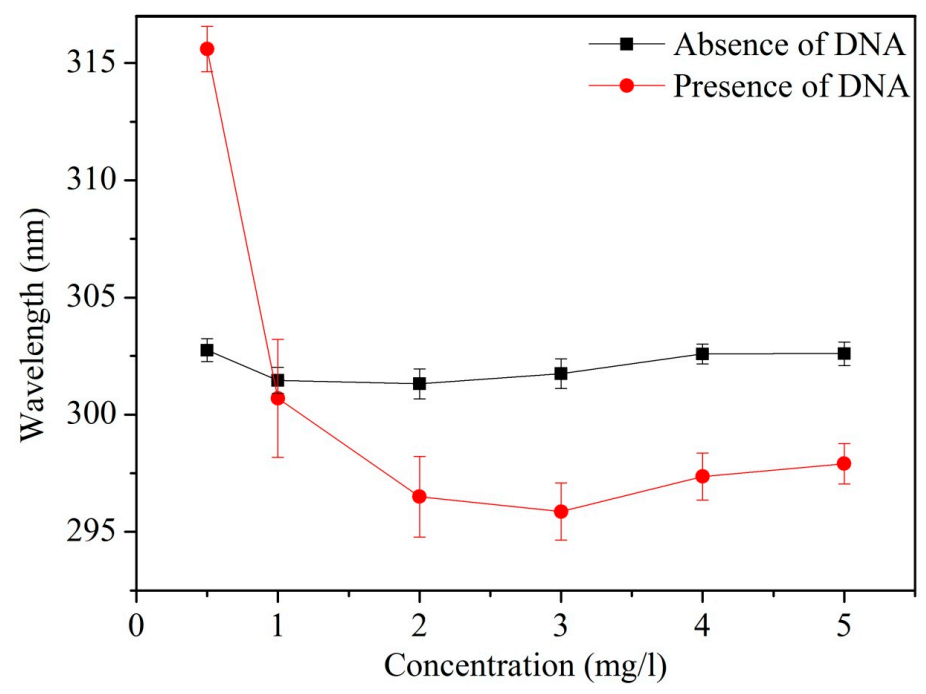

Figure 1. Peak shift of dye in presence and absence of DNA. Each data point in the graph denotes Mean \pm Standard errors.

\subsection{Spectroscopic Study of Dye in SDS Micelles}

Figure 2 represents the absorbance spectrum of dye in presence of SDS micelle. The dye exhibited a $\sim 20 \mathrm{~nm}$ red shift compared to water in the presence of SDS micelle. The shift may be due to electrostatic interaction between dye and SDS micelle. As SDS micelles were negatively charged, the dye must be positively charged to show this type of interaction. However, we were not able to find any significant change in fluorescence spectrum with respect to water, which confirms the surface attachment and inaccessibility of nonpolar environment of micelle of the dye. 


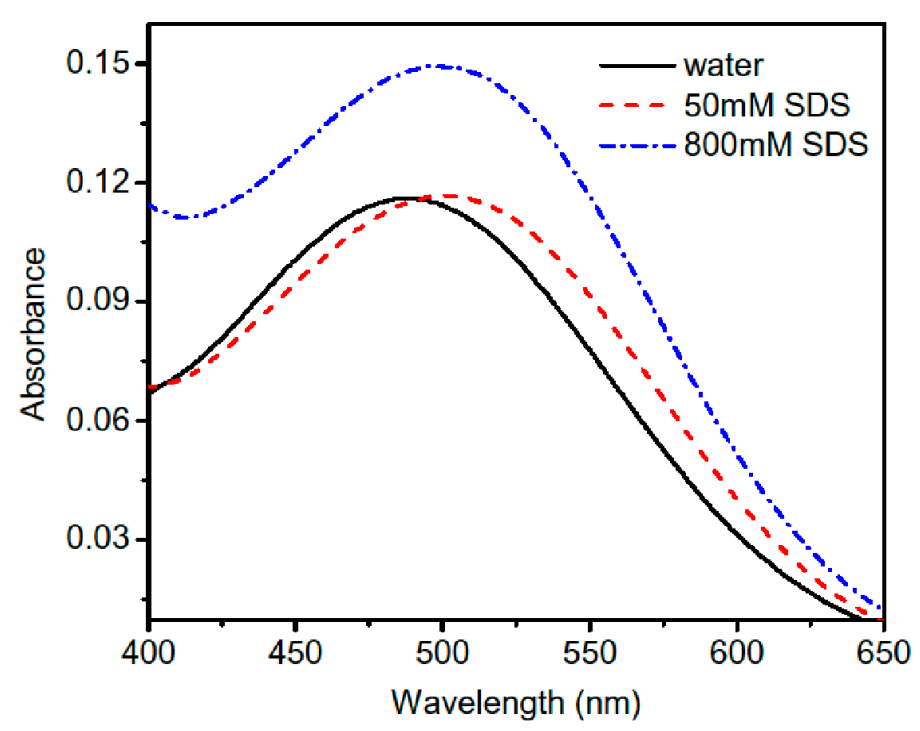

Figure 2. Absorption Spectra of Dye in Water and in Different Concentration of Sodium Dodecyl Sulfate (SDS).

\subsection{UV-vis Spectroscopic Studies on Autoxidation of Dye}

It was found that, in the presence of Fe(III), the maximum absorbance of dye at $280 \mathrm{~nm}$ and $485 \mathrm{~nm}$ increases with time but in absence of Fe(III), absorbance did not change significantly (data not shown). Figure 3 represents the change of absorbance of dye with time in presence of Fe(III). This indicates the higher possibility of electron transfer between dye and Fe(III), generating reactive oxygen species which may cause DNA damage. Yoshida et al. had shown that the amount of cleaved plasmid DNA increased along with the concentration of Fe(III) in presence of dye components [9]. However, we performed all our experiments with a usable form of dye, without any inducer. This implies that commercial dyes were more susceptible to toxicity than individual ingredients. Autoxidation of dye increases the possibility of electron transfer of hair dye in biological medium which may induce toxicity and mutation in a DNA sequence.

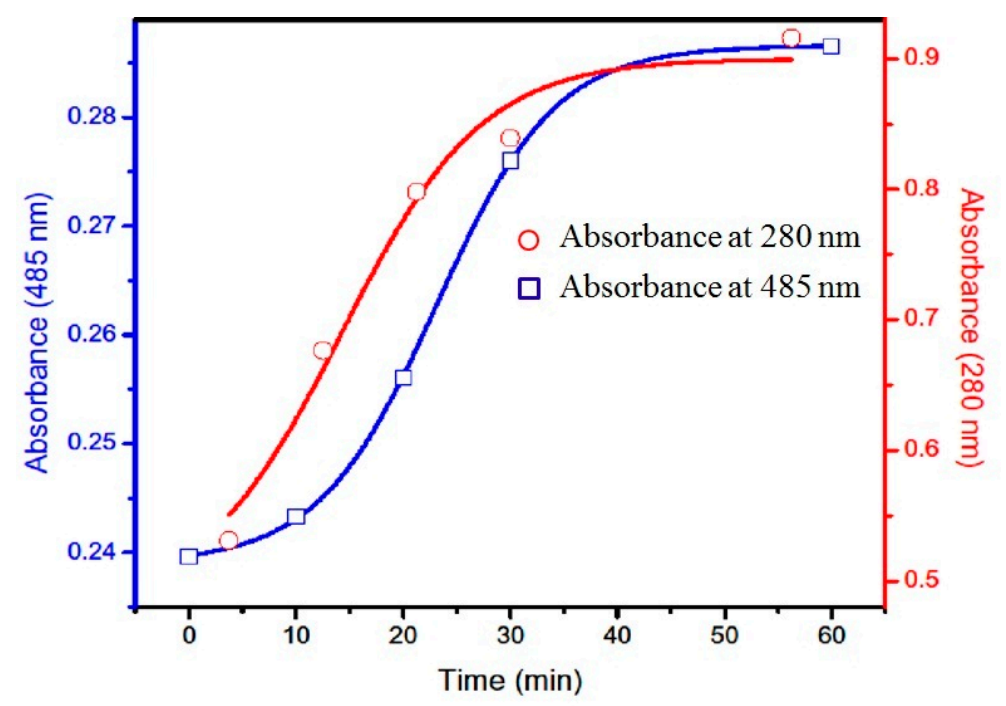

Figure 3. Absorbance spectrum of hair dye with time in presence of $\mathrm{Fe}(\mathrm{III})$ at $280 \mathrm{~nm}$ and $485 \mathrm{~nm}$. 


\subsection{Study of Dye-DNA Interaction Using Agarose Gel Electrophoresis}

To check the type of binding of dye with DNA we treated dye with calf thymus DNA. Figure 4a represents the gel picture of calf thymus DNA with dye collected from gel documentation system and Figure $4 \mathrm{~b}$ is the in situ visual picture of same gel. From Figure 4a, we observed the movement of DNA was towards the positive electrode; however, dye movement was towards the negative electrode (Figure 4b) during electrophoresis. From Figure 4b it was clear that dye was mostly bound through electrostatic interaction with the negative backbone of the DNA [21]. The movement of free dye towards the negative field and DNA towards the positive field happed due to separation of dye-DNA complex in the presence of a strong electric field. It was found that at low dye concentration $([$ dye]:[DNA] $=1: 2$ ) structural deformation was not very prominent (lane 3); however, at 10:1 concentration, DNA became fragmented (lane 2) and completely smeared at [dye]:[DNA] = 100:1 (lane 4), indicating complete fragmentation of DNA. This may be due to the electron transfer between dye and DNA. Figure 1 indicates the possibility of electron transfer between dye and DNA. Figure 2 specifies the electron transfer between dye and SDS. SDS is negatively charged, so for electron transfer, dye or dye component must have positive charge.

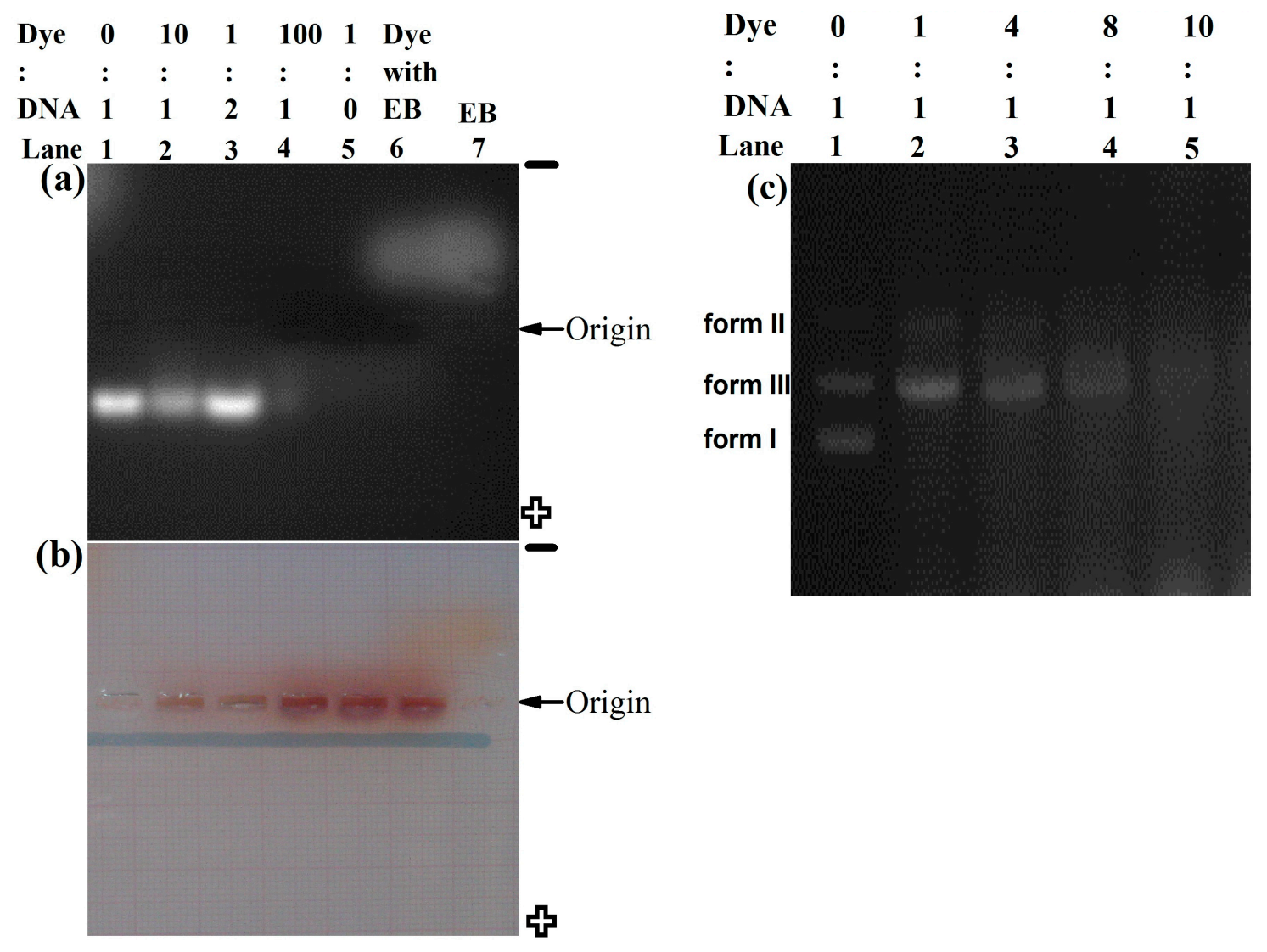

Figure 4. Gel electrophoresis study. (a) lane 1 calf thymus DNA without dye, lane 2 $([$ dye $]:[D N A]=10: 1)$, lane $3([$ dye $]:[D N A]=1: 2)$, lane $4([$ dye]:[DNA $]=100: 1)$, lane 5 Dye without DNA, lane 6 dye with $10 \mu \mathrm{g}$ Ethidium Bromide (EB), lane 7, $20 \mu \mathrm{g}$ Ethidium Bromide. (b) Visual picture of (a). (c) Gel with plasmid DNA (pUC 18) and dye. Lane 1 plasmid DNA without dye, lane 2 ([dye]:[DNA] $=1: 1$ ), lane 3 ([dye]:[DNA] = 4:1), lane 4 ([dye]:[DNA] $=8: 1)$, lane $5([$ dye $]:[\mathrm{DNA}]=10: 1)$. 
From Figure 4 the nature of electric charge of dye and the oxidizing property of dye is also clear. Dye has several ingredients of electron donating and accepting group. So DNA gets oxidized in absence of any inducer. According to the possible reaction mechanism of different dye components, highly reactive radical is formed in intermediate states. At very low concentration of dye, the effect is not very prominent. However, at higher concentrations of dye, the concentration of generated radical increases, hence, the possibility of electron transfer with DNA increases, leading to DNA fragmentation. Most of the dye became free after the fragmentation of DNA by electron transfer reaction via radical intermediate that can be separated easily by electric field. Similar experiments were performed with plasmid DNA (pUC 18), represented in Figure 4c. We observed that with increasing concentration of dye, supercoiled plasmid DNA (form I) was transformed into linear (form III) followed by nicked DNA (form II). Yoshida et al. observed a similar type of fragmentation with increasing concentration Fe(III) [9]. However, a usable form of hair dye showed DNA fragmentation without any catalyst such as Fe(III), indicating the high toxicity of hair dye.

\section{Conclusions}

In the present study, we explored the plausible mechanism of dye-DNA interaction towards the genotoxic effect of hair dye. In vitro studies of dye-DNA interaction in absence of any catalyst causes fragmentation and oxidation of DNA, implying high toxicity of the hair dye in its usable state. As the chemical and physical properties of DNA are more or less similar in all cellular organisms, the candidate dye may show a similar effect in human physiology and thus, may induce adverse health effects. The interaction of the hair dye with DNA indicates that application of such dye may lead to penetration through the skin affecting the genomic DNA. This study will possibly increase awareness regarding the internal effects of hair dye use in humans.

\section{Acknowledgements}

The authors are thankful to Department of Biotechnology, Haldia Institute of Technology for providing necessary facilities to carry out the experiments of this work. Jaydev Dinda is greatly acknowledged for providing lab facilities for spectroscopic studies. Authors are thankful to Pranab Roy for useful advices and suggestion during the reviewing process of manuscript. We are also thankful to Jyoti Doley of our Institute and Nidhi Singh for language correction.

\section{Author Contributions}

Swati Maiti had carried out the dye-DNA interaction studies and drafted the manuscript. Sudarson Sekhar Sinha had analyzed the interaction study. Mukesh Singh had conceived the work, jointly carried out the interaction studies and editing the manuscript.

\section{Conflicts of Interest}

The authors declare no conflict of interest. 


\section{References}

1. Bartman, E. Hair and the artifice of Roman female adornment. Am. J. Archaeol. 2001, 105, 1-25.

2. Corbett, J.F. An historical review of the use of dye precursors in the formulation of commercial oxidation hair dyes. Dyes Pigment. 1999, 41, 127-136.

3. Brown, K.C. Hair coloring. In Hair and Hair Care; Marcel Dekker: New York, NY, USA, 1997.

4. Monnais, C. Hair color alterations agent. In Cosmetics-Development, Manufacture and Application of Cosmetics; Georg Thieme Verlag: Stuttgart, Germany, 1995.

5. Ames, B.N.; Kammen, H.O.; Yamasaki, E. Hair dyes are mutagenic: Identification of a variety of mutagenic ingredients. Proc. Natl. Acad. Sci. 1975, 72, 2423-2427.

6. Garrigue, J.L.; Ballantyne, M.; Kumaravel, T.; Lloyd, M.; Nohynek, G.J.; Kirkland, D.; Toutain, H. In vitro genotoxicity of para-phenylenediamine and its $N$-monoacetyl or N,N'-diacetyl metabolites. Mutat. Res. Genet. Toxicol. Environ. Mutagen. 2006, 608, 58-71.

7. Cosmetic Ingredient Review Expert Panel. Final report on the safety assessment of disperse Blue 7. Int. J. Toxicol. 2007, 26, 65-77.

8. Murata, M.; Nishimura, T.; Chen, F.; Kawanishi, S. Oxidative DNA damage induced by hair dye components ortho-phenylenediamines and the enhancement by superoxide dismutase. Mutat. Res. Genet. Toxicol. Environ. Mutagen. 2006, 607, 184-191.

9. Yoshida, R.; Oikawa, S.; Ogawa, Y.; Miyakoshi, Y.; Ooida, M.; Asanuma, K.; Shimizu, H. Mutagenicity of $p$-aminophenol in E. coli WP2uvrA/pKM101 and its relevance to oxidative DNA damage. Mutat. Res. Genet. Toxicol. Environ. Mutagen. 1998, 415, 139-150.

10. Burnett, C.M.; Corbett, J.F. Failure of short-term in vitro mutagenicity tests to predict the animal carcinogenicity of hair dyes. Food Chem. Toxicol. 1987, 25, 703-707.

11. Haws, L.C.; Jackson, B.A.; Turnbull, D.; Dressler, W.E. Two approaches for assessing human safety of disperse Blue 1. Regul. Toxicol. Pharmacol. 1994, 19, 80-96.

12. Genina, E.A.; Bashkatov, A.N.; Sinichkin, Y.P.; Kochubey, V.I.; Lakodina, N.A.; Altshuler, G.B.; Tuchin, V.V. In vitro and in vivo study of dye diffusion into the human skin and hair follicles. J. Biomed. Opt. 2002, 7, 471-477.

13. Yourick, J.J.; Bronaugh, R.L. Percutaneous penetration and metabolism of 2-nitro-p-phenylenediamine in human and fuzzy rat skin. Toxicol. Appl. Pharmacol. 2000, 166, 13-21.

14. Steiling, W.; Kreutz, J.; Hofer, H. Percutaneous penetration/dermal absorption of hair dyes in vitro. Toxicol. in vitro 2001, 15, 565-570.

15. Burnett, C.; Fuchs, C.; Corbett, J.; Menkart, J. The effect of dimethylsulfoxide on the mutagenicity of the hair dye $p$-phenylenediamine. Mutat. Res. 1982, 103, 1-4.

16. Bracher, M.; Faller, C.; Grotsch, W.; Marshall, R.; Spengler, J. Studies on the potential mutagenicity of $p$-phenylenediamine in oxidative hair dye mixtures. Mutati. Res. 1990, 241, 313-323.

17. Crebelli, R.; Conti, L.; Carere, A.; Zito, R. Mutagenicity of commercial p-phenylenediamine and of an oxidation mixture of $p$-phenylenediamine and resorcinol in salmonella typhimurium TA98. Food Chem. Toxicol. 1981, 19, 79-84.

18. Watanabe, T.; Kawata, A.; Koyanagi, T. Mutagenicity of hair dyes. J. Soc. Cosmet. Chem. Jpn. 1980, 41, 20-25. 
19. Spengler, J.; Bracher, M. Toxicological tests and health risk assessment of oxidative hair dye mixtures. Cosmet. Toilet. 1990, 105, 67-76.

20. Maiti, S.; Sasmal, K.; Sinha, S.S.; Singh, M. Analysis of cytotoxicity and genotoxicity suggests a greater toxic potential of hair dye. Ecotox. Environ. Safe 2015, submitted.

21. Mitra, R.K.; Sinha, S.S.; Maiti, S.; Pal, S.K. Sequence dependent ultrafast electron transfer of Nile Blue in oligonucleotides. J. Fluoresc. 2009, 19, 353-361.

22. Maiti, S.; Maiti, P.; Sinha, S.S.; Mitra, R.K.; Pal, S.K. Molecular recognition of plant DNA: Does it differ from conventional animal DNA? Int. J. Biol. Macromol. 2009, 44, 133-137.

23. Patist. A.; Kanicky, R.J.; Shukla, K.P.; Shah, O.D. Importance of micellar kinetics in relation to technological processes. J. Colloid Interface Sci. 2002, 245, 1-15.

24. Lakowicz, R.J. Principles of Fluorescence Spectroscopy; Springer: Berlin, Germany, 2010.

(C) 2015 by the authors; licensee MDPI, Basel, Switzerland. This article is an open access article distributed under the terms and conditions of the Creative Commons Attribution license (http://creativecommons.org/licenses/by/4.0/). 